\title{
Change during psychotherapy: the perspective of children and adolescents who have been sexually abused
}

\author{
Claudia Capella, Carolina Gutiérrez, Loreto Rodríguez, Camila Gómez \\ Department of Psychology, University of Chile, Chile
}

\begin{abstract}
The aim of this research was to identify the meanings of psychotherapeutic change of children and adolescents who have suffered sexual abuse and were in psychotherapy. In order to do this, a qualitative study was carried out in which in-depth interviews complemented with drawings were conducted with 10 children and adolescents, aged between 6 and 16 years, who were taking part in psychotherapy due to sexual abuse. The interviews took place between 6 and 10 months after the start of the therapy and before it ended. Thematic narrative analysis was used for the interviews and visual narrative analysis for the drawings. The main findings showed that children and adolescents visualized psychotherapeutic change as a process in which gradual progress is made. The participants notice changes from an initial state of sadness and distress, mainly describing a positive shift in terms of emotional well-being. In addition, in this phase of the therapy only a few participants identified changes in their feelings regarding the abusive experience. The participants identified aspects of the therapy and supportive relationships with significant others as elements that foster these changes. In their view, hindering elements include changes of therapist, legal factors, and not being believed by their family. It is discussed the importance of knowing the children and adolescents' perspective regarding psychotherapeutic change while participating in therapy processes, using multiple methodologies, to generate interventions that suit the needs of this population and match the pace of children and adolescents' change.
\end{abstract}

Key words: Child psychotherapy research; Change in psychotherapy; Narrative analysis.

\section{Introduction}

Psychotherapeutic change has received extensive scholarly attention in the field of psychotherapy research

Correspondence: Claudia Capella, Department of Psychology, University of Chile, Avenida Capitán Ignacio Carrera Pinto 1045, Ñuñoa, Zip Code 6850331, Santiago, Chile.

Tel.: +56.229772410

E-mail: ccapella@u.uchile.cl

Contributions: CC participated and led different phases of the research and writing process. CG participated in the writing process. LR contributed to analysis and writing. CG contributed to analysis and literature review.

Conflict of interest: the authors declare no potential conflict of interest.

Acknowledgments: the authors would like to thank the project research team that made this study possible, as well to the centers and participants.

Funding: the research presented in this paper was funded by CONICYT Project Fondecyt N ${ }^{\circ} 11140049$.

Received for publication: 17 August 2017

Revision received: 23 October 2017

Accepted for publication: 14 November 2017.

This work is licensed under a Creative Commons Attribution NonCommercial 4.0 License (CC BY-NC 4.0).

CCopyright C. Capella et al., 2018

Licensee PAGEPress, Italy

Research in Psychotherapy:

Psychopathology, Process and Outcome 2018; 21:24-39

doi:10.4081/ripppo.2018.288
(Altimir et al., 2010; Krause 2005; Krause et al., 2006). It has been defined as a change in a person's subjective patterns of interpretation and explanation that leads to the development of new subjective theories (Krause, 2005, p. 333, own translation), while subjective theories could be defined as a complex set of personal cognitions that help guiding individual behavior (Altimir et al., 2010). This complex group of cognitions or self-narratives are believed to configure a matrix that makes it possible to organize the self and its relationships, thus giving meaning to individuals' experiences and granting continuity to the meaning that guides their lives (Capella, 2011; Gonçalves, Matos, \& Santos, 2009).

This change process affecting subjective patterns is believed to evolve over successive stages that start before the therapy and continue after it ends, combining both intra and extra-therapeutic factors. This process, thought to be nonlinear, appears to involve a progressive increase in the complexity of the psychological patterns of explanation and interpretation. Moreover, during psychotherapy, this process seems to involve the construction of phases leading to the successive psychologizing of these subjective patterns (Altimir et al., 2010; Krause 2005; Krause et al., 2006).

Studies on psychotherapeutic change are mainly focused on adult populations (Altimir et al., 2010; Gonçalves et al., 2009; Krause, 2005; Krause et al., 2006), with only a few of them considering children and adolescents (Carlberg, Thoren, Billstrom, \& Odhammar, 2009; Fernández, Pérez, Glober, \& Krause, 2015; Fernández, Krause \& Pérez, 2016; Midgley, 2004). In addition, 
studies on psychotherapeutic change in children and adolescents have mainly been based on reports by adult third parties, such as parents or psychotherapists (Carlberg, 1997), while only a small number has highlighted children and adolescents' own meanings (Carlberg et al., 2009).

Specifically, research into the psychotherapeutic change that children and adolescents with sexual abuse experiences can undergo in therapy has mainly focused on the assessment of symptomatological change. The same occurs in most of the psychotherapy research carried out with general clinical populations (Hetzel-Riggin, Brausch, \& Montgomery, 2007; Sanchez-Meca, Rosa-Alcázar, \& López-Soler, 2011).

Regarding child and adolescent sexual abuse (CSA), high prevalence rates have been observed worldwide (Pereda, Guilera, Forns, \& Gómez-Benito, 2009), a reality that is also present in Chile, where $9 \%$ of children and adolescents report having experienced sexual abuse (UNICEF, 2012). The specialized literature shows that these experiences often lead to negative consequences, both in the short and the long term which might affect different developmental areas (Cantón \& Cortés, 2004; Echeburúa \& Corral, 2006; Pereda et al., 2009). In addition, research has shown the effectiveness of psychological interventions to deal with the consequences of sexual abuse (Hetzel-Riggin et al., 2007; Sanchez-Meca et al., 2011). Consequently, treatment is considered to be necessary in such cases. The approach used considers psychotherapy as an essential component of interdisciplinary treatment (CAVAS, 2011).

From a theoretical-clinical perspective, it has been asserted that psychotherapy with child and adolescent victims of sexual abuse is mainly aimed at supporting the resignification of the abusive experience, a process in which the person should be able to integrate the abuse into his/her life history, resignifying it in an adaptive manner (Capella \& Gutierrez, 2014; Capella et al., 2016). In addition, some authors consider that sexual abuse victims undergo a dynamic process, which includes both recovery and growth and which allows them to heal from the abusive experience (Draucker et al., 2011). This process is believed to involve several stages that occur throughout a person's life, with moments of progress and regression (Banyard \& Williams, 2007; Harvey, Mishler, Koenen, \& Harney, 2000).

Despite the importance of psychotherapy and psychotherapeutic change in these cases, international studies on CSA are mostly focused on the general characteristics of the phenomenon, psychological diagnosis, and/or legal proceedings and evidence (Malacrea, 2000). Studies involving psychotherapy, especially those that incorporate the participants' own perspectives, are less common (Capella et al., 2016; Foster \& Hagedorn, 2014; Jessiman, Hackett, \& Carpenter, 2017; Nelson-Gardell, 2001).

Over the last years, some studies have described children and adolescents' perception of their healing process from sexual abuse and the psychotherapy associated with it (Capella et al., 2016, Foster \& Hagedorn, 2014; Jessiman et al., 2017; Nelson-Gardell, 2001). Nevertheless, these studies only included the views of children and adolescents after the completion of the psychotherapeutic process (Capella et al., 2016; Jessiman et al., 2017), involving group interviews (Nelson-Gardell, 2001), or including an analysis of materials written by the participants during the psychotherapy (Foster \& Hagedorn, 2014) without individually asking the children and adolescents about their opinions regarding the psychotherapy and their own changes during the therapeutic process.

Considering children and adolescents' perspectives during the psychotherapy is relevant because it has been observed that psychotherapy in general, and specifically in these cases, involves several moments that possess differential characteristics (Águila et al., 2016; Altimir et al., 2010; Echávarri et al., 2009; Gonçalves et al., 2009). Therefore, research that inquiries into participants' views only during the final phase of therapy could be losing their perspectives during the psychotherapy, which may well differ from their final opinion and serve to inform treatment at multiple stages of the process. Moreover, there is a long research tradition that highlights the importance of considering patients' views throughout the psychotherapy providing rich and relevant information to improve the interventions in the clinical practice (Elliot, 2008).

Within the context of the larger research project to which the present study belongs, Gómez (2016) has developed a systematization and a theoretical proposal showing how psychotherapeutic change can be understood in child and adolescent victims of sexual abuse. In order to do this, the study of Gómez (2016) integrates the knowledge obtained from previous research on psychotherapy and healing from sexual abuse considering the views of the victims (Banyard \& Williams, 2007; Capella et al., 2016; Draucker et al., 2009, 2011; Foster \& Hagedorn, 2014; Harvey et al., 2000; Jessiman et al., 2017; Nelson-Gardell, 2001; Phanichrat \& Townshend, 2010; Phillips \& Daniluk, 2004; Saha, Cheung, \& Thorne, 2011) and the theoretical-clinical conceptualizations of psychotherapy in sexual abuse cases (Barudy, 1998; Cantón \& Cortés, 2004, Capella \& Gutierrez, 2014; Gil, 2006; Llanos \& Sinclair, 2001; Malacrea, 2000), complemented with the results of research on psychotherapeutic change (Altimir et al., 2010; Echávarri, et al., 2009; Gonçalves et al., 2009; Krause, 2005; Krause et al., 2006) and psychotherapy with children and adolescents in the general clinical population (Binder, Moltu, Hummelsund, Sagen., \& Holgersen, 2011; Bury, Raval, \& Lyon, 2007; Carlberg, 1997; Carlberg et al., 2009; Caroll, 2002; Fernández, 2013; Gibson \& Cartwright, 2014; Midgley, 2004; Midgley, Target, \& Smith, 2006; Stith, Rosen, McCollum, Coleman, \& Herman, 1996). 
From this point of view, Gómez (2016) suggests that psychotherapeutic change in this population involves the gradual construction of a narrative that emerges as an alternative to a traumatic narrative of the abusive experience, allowing the person to give meaning to it and integrate it positively into the continuum of life as one experience among many - as something that does not determine his/her life and future (Capella, 2011; Capella et al., 2016; Neimeyer, Herrero, \& Botella, 2006; Ronen, 1996). By making sense of the sexual abuse experienced, children and adolescents not only recover from this event but also grow up and become stronger, generating a global transformation in their view of themselves, their relationships, and their environment (Capella \& Gutiérrez, 2014; Capella et al., 2016; Draucker et al., 2011).

In relation to the psychotherapy phases in which this psychotherapeutic change occurs, Gómez (2016) proposes that the child and adolescent victims of sexual abuse go through three major stages: initial, middle, and final. The initial stage, during which they enter the psychotherapeutic space, appears to be difficult, generating ambivalence and activating a set of resistance mechanisms in children and adolescents. An important change in this stage concerns the lowering of these resistance mechanisms, with psychotherapy becoming increasingly valid as a safe place and a helpful space, for which the initial consolidation of the therapeutic alliance is essential. In the middle phase, the elaboration of the sexual abuse experienced becomes more intensive, which allows the person to clearly understand the traumatic event and its dynamics. The final phase of change appears to be linked to various interconnected aspects, involving the consolidation of what patients have constructed in previous phases and the visualization of their achievements. In this last stage, patients should present more wellbeing, which occurs when the patient achieves a deep understanding and awareness about the abusive experience. Moreover, the patient assumes that he/she will always remember the event, but this memory is evoked with a smaller negative emotional impact.

Complementing the theoretical integration proposed by Gómez (2016), it can be stated that the content of psychotherapeutic change in sexually abused children and adolescents involves transformations in several spheres, such as symptomatic remission, changes in interpersonal relationships, a better identification and expression of emotions, and a clearer comprehension of their sexuality, among others. In addition, this change is considered as a phenomenon that is influenced by multiple factors, both intra- and extra-therapeutic, which may have a positive or a negative effect.

Thus, the literature has described psychotherapy and the therapist's empathetic traits as some of the main positive elements within the process, along with the use of verbal and nonverbal techniques in the therapy and longer intervention periods. On the one hand, studies have identified extra-therapeutic factors associated with a positive impact on change during the therapy. These factors are linked to the patient's family and social context, particularly family support and help from parental figures along with a socio-familial reaction of belief in the patient's disclosure of the abuse suffered. The absence of the aforementioned family and social elements constitutes a hindering factor that makes the recovery process more difficult (Gómez, 2016). On the other hand, related to contextual factors, researchers have noted that contact with the judicial system can both facilitate and hinder the patient's recovery (Capella et al., 2016; Lama et al., 2015). The personal factors described in the literature as facilitators of change include patients' personal determination and internal drive for coping with and continuing the therapeutic process (Gómez, 2016).

Despite the value of this conceptualization developed by Gómez (2016), this theoretical-clinical perspective and its associated literature review must be complemented with empirical research that considers the views of children and adolescents. Consequently, the aim of the present study is to describe psychotherapeutic change from the point of view of children and adolescents who have been sexually abused and are taking part in a psychotherapeutic process due to this experience.

Authors have described the methodological difficulties involved in studying children and adolescent populations in psychotherapy research (Carlberg et al., 2009). Probably for this reason, most psychotherapy research has privileged the inclusion of adult perspectives to the detriment of those of children. Nevertheles, when children are incorporated, researchers tend to use traditional methods such as surveys and interviews, mostly using verbal strategies to gather information (Bradding \& Horstman, 1999; Heinzel, 1997). However, some authors (Capella et al., 2015; Carlberg et al., 2009) stress the importance of using both verbal and nonverbal techniques to incorporate the perspectives of children and adolescents into psychotherapy research. These techniques should facilitate communication with children, making it possible to approach them differently, in a way that validates their views (Driessnack, 2005). In addition, specifically with respect to children and adolescents who have been sexually abused, researchers point out that the lack of studies incorporating this perspective may be to the victimization risks that participation entails (Foster \& Hagedorn, 2014); therefore, relevant ethical safeguards and non-intrusive techniques must be employed.

In consequence, the present study incorporated nonverbal as well as verbal methods during the interviews with children and adolescents, specifically including graphic techniques intended to foster the participants' narrative production and provide multiple ways of gaining access to their experiences. Drawings are a natural means of expression and a tool that makes it possible to identify the meanings that children ascribe to their experiences (Kuhn, 2003). 


\section{Methods}

The present study is part of a larger project aimed at characterizing the content and phases of psychotherapeutic change in child and adolescent victims of sexual abuse, incorporating their perspective and that of their parents and psychotherapists at several moments of the psychotherapeutic process. The study is qualitative and longitudinal, aiming at gaining an in-depth understanding of the participants' meanings regarding psychotherapeutic change at different moments in the process.

\section{Participants}

The subsample that participated in this study is composed of 10 children and adolescents aged between 6 and 16 years, who have been victims of sexual abuse and are currently receiving psychotherapy for this reason in public centers specialized in the treatment of sexual abuse in Chile (in the study 6 centers from 4 different institutions participate. The institutions that colaborate with the study were: CAVAS from Policía de Investigaciones de Chile, Corporación Opción, Fundación Ciudad del Niño CODENI, and Fundación Mi Casa). It should be noted that even though several centers participated in the study, they all belong to the collaboration network of SENAME, the institution in charge of children's issues in Chile, which has established common intervention guidelines for these cases (SENAME, 2014). Said guidelines establish that therapy can range from 12 to no more than 18 months in sexual abuse cases. Children were included in the study as sexual abuse victims according to the professional assessment conducted by each center during the diagnosis stage. Table 1 displays the specific characteristics of the sample.

On average, the participants have been in therapy for 8 months, ranging from 6 to 9 months. During this period, each child or adolescent participated in 14 to 26 psychotherapy sessions. Thus, considering the maximum intervention length at these centers, these therapies were considered to be in their initial or middle phase. More-

Table 1. Sample characteristics.

\begin{tabular}{lcc}
\hline Characteristic & Categories & Number \\
\hline Age & Children aged 6-11 years & 7 \\
& Adolescents aged 12-16 years & 3 \\
\hline Gender & Females & 8 \\
& Males & 2 \\
\hline Offender & Relative & 6 \\
& Paternal or maternal figure & 3 \\
\hline Type of abuse & Acquaintances & 1 \\
\hline \multirow{2}{*}{ Chronicity of the abuse } & Sexual abuse & 9 \\
& Rape & 1 \\
\hline
\end{tabular}

over, therapies were carried out on a regular basis in individual sessions with the child or adolescents. Also, their parents attended sessions with a psychologist or a social worker, supporting in this way the child' process. Dialogue and different play and creative techniques were used in therapy, depending on the characteristics of the case. The guidelines of the treatment centers, generally assume in their practices that children and adolescents know the reason for being in those centers.

Also, purposive sampling was used, since only the cases that met the inclusion criteria were selected. Theoretical or strategic sampling was employed: the interviewees were expected to represent different possible discursive positions based on the attributes used to characterize the group, such as age, type of abuse, and relationship with the attacker, among others (Valles, 2003).

\section{Data production techniques}

Data were collected through qualitative interviews, which make it possible to preserve participants' subjectivity (Valles, 2003). During the interview, the participants were invited to produce a narrative of the psychotherapy process up to that point, an account of how they thought psychotherapeutic change had occurred, and a list of the factors that in their opinion foster or hinder change. In order to do this, interview scripts were created around three overall themes: i) Description and meanings of psychotherapeutic change (what changes and how), ii) Characterization of the psychotherapeutic process, and iii) Factors considered to foster and hinder change (both intraand extra-therapeutic elements).

Apart from the interview, drawings were used to complement the participants' verbal narratives. To do this, a specific drawing format was used: an adaptation of the technique known as before and after therapy. This technique is often used in Chile in psychotherapy with sexual abuse victims, having already been adapted and employed in studies with this population (Capella et al., 2015, 2016). The adapted drawing used in this study is a template in which the page is divided into two parts. The left-hand side reads how were you at the start of the therapy?, while the other half reads how are you now? This material is used to invite the participant to draw him/herself at these two moments. Black and colored pencils and an eraser were provided to encourage creativity and spontaneity.

In addition, during the interviews the children were shown a drawing of an emotional thermometer which was explained to them. This is a visual support technique modified from Carlberg et al., 2009. The drawing ranged from 0 , which was identified as very sad, to 10 , labeled very happy. With this graphic support, children were asked to report how they felt at various points of the therapy process (at the beginning, at present, and how they would like to feel at the end of the therapy).

Considering developmental differences, in the case of the younger children, the use of drawings and the ther- 
mometer were encouraged during the interviews in order to help the development of their narratives. Questions in the scripts used a language that was understandable by children. To ensure this, some pilot interviews were developed at the beginning. In contrast, adolescents usually give a more clearly verbal account, thus questions during the interview were privileged and the drawing was used only as a complement at the end of the interview.

\section{Procedure}

In order to conduct the study, approval was first obtained from the Committee on Ethical Research in Social Sciences at the Faculty of Social Sciences of the University of Chile. Afterwards, the authorization from the directors of the participating centers was secured. Then, the project was presented to the therapists, who signed an informed consent form when they agreed to participate. Third, the children and adolescents, along with their caregivers, were contacted through the psychotherapists at the beginning of the therapy. The professionals explained the study and invited them to participate voluntarily. After they agreed, the adults were asked to sign an informed consent letter, while children were required to provide their assent.

Between 6 and 9 months after this first contact, the interviews with the participants were scheduled. Since the therapists had the clearest view of the cases and their contingent elements, they were in charge of deciding whether that was a suitable moment for the interview or not. This procedure allowed to conduct the interviews at times that would be appropriate for the participants, thus preventing further interference in their therapeutic process. The interviews were carried out by members of the research team specialized in clinical work with children and adolescents at the center where they usually received therapy. The interviews were audio recorded and later transcribed. In the interview transcripts, identification data were changed to preserve the participants' anonymity.

Finally, as an ethical safeguard, to protect the wellbeing of the participating children and adolescents, the interviews conducted during the therapeutic process privileged the use of graphical techniques over verbal narration. Due to their low invasiveness, they were expected to cause less interference in the psychotherapeutic process.

\section{Data analysis}

The information obtained through interviews was analyzed following narrative analysis guidelines. Each interview was individually analyzed considering its thematic narrative aspects. The graphic products obtained were visually analyzed (Capella et al., 2015; Riessman, 2008). The narrative analysis of the material gathered was aimed at obtaining narratives or stories of the therapeutic process, which were expected to shed light on events in the participants' life - in this case, their participation in a psychotherapeutic process - and the particular meanings ascribed to psychotherapeutic change by each participant. This objective was achieved through the analysis of multiple means of expression, distinguishing several ways in which the narratives are organized, interpreted, and signified by the participants which can be complemented to obtain in-depth information about the phenomenon.

Several codes emerged from the individual analysis, which gave rise to topics that were grouped at multiple analysis levels. The general topics considered were the content of change, how it occurs, and the factors that influence it. In parallel, the drawings used during the interview were examined. A visual analysis (structure, use of space, etc.) was complemented by the participants' references to the drawing during the interview.

Afterwards, an inter-case analysis was conducted, which consisted in an integrated analysis of all the interviews and products obtained, which yielded common and differential aspects. In order to meet validity and quality criteria in qualitative research and narrative analysis (Midgley, 2004; Riessman, 2008), triangulation was used during the analysis stage: several researchers took part in the qualitative data analysis process, so that the identification and interpretation of the narrative themes generated could be validated through intersubjective agreement. The analysis of the interviews and drawings was more efficiently made by using ATLAS.TI v7, a program designed for managing and processing textual and visual data.

\section{Results}

The main thematic areas that emerged from the analysis of the interviews were: i) What changes?, that is, the content of the change; ii) How does it change?, that is, how the psychotherapeutic change process occurs; iii) What factors influence the likelihood of change?. It is important to mention that generally, there were similarities in the results obtained from children and adolescents. However, some evolutive differences that were observed are pointed out below.

\section{What changes?}

The participating children and adolescents noticed and reported changes in themselves which were also perceived by significant others in their social context. They expressed that friends and relatives had alluded to these changes. This generated a feeling of well-being in them.

With respect to the content of change, participants mentioned that they perceived an overall change and were also able to identify specific changes in the affective, relational, cognitive, and social areas, among others. In addition, some interviewees reported changes linked to the sexual violence experienced. It is noteworthy that the children also observed changes in their parents. 


\section{Affective changes}

All the participants stressed the importance of the emotional changes currently observed when comparing themselves with at the beginning of the treatment. This was the most frequently highlighted change in the participants' narratives. With respect to the initial phases of the therapy, they mainly described the presence of feelings such as sadness, fear, and nervousness. At the moment of the interviews, patients reported fewer crying episodes as well as a few situations in which they felt irritable, distressed, or angry. Also, most of the interviewees noted that this change was reflected in an improvement of their mood: they felt happier, calmer, and more positive, and therefore experienced more emotional relief and greater overall well-being. Thus, the changes reported were directly related to symptomatological remission.

I was sad before and now I'm happy. (Paloma, 7 years old)

I'm happier, I get up in the morning in a better mood, now I'm more interested in school, I do my homework, I do lots of things, now I'm going to a dance workshop. (Isabel, 10 years old)

These changes were also identified in the participants' drawings. Many participants drew themselves with different facial expressions in the before and now figures, initially showing sadness, nervousness, and displeasure but then changing to expressions of happiness which were clearly displayed through smiles. Some of these elements can be observed in Figure 1.

This shift to a state of greater well-being can also be observed through the visual support technique (thermometer), with which the participants quantified their progress in emotional terms. Thus, with the support of this visual technique, all the participants used the first numbers in the thermometer $(1,2$, and 3$)$ to express their emotional state at the start of the therapy, conveying feelings of distress. In contrast, they chose higher numbers to refer to the present time of the therapy $(8,9$, and 10$)$, which was characterized by feelings of emotional well-being. This can be observed in Figure 2 .

\section{Relational changes}

The participants described changes in their relationships with their family and friends. They refered to previous moments when they had felt far from their family nucleus, mainly characterized by a lack of communication and low emotional support. The participants highlighted the presence of relational changes with their adult caregivers, generally their maternal figure. They behaved differently towards this figure, interacting with her in a more positive manner due to feeling more trust and a stronger affective bond.
Before I couldn't talk with my family, I couldn't said what I feel, what bothers me, and now I can, we talk through everything; sometimes while we are watching to with my mom, we are bored and we start talking. (Denise, 9-year-old)

In addition, some participants also stated that they could observe changes in their relationship with their family, as they felt a more intimate bond with them. Finally, in this sphere, some interviewees noted that they had seen improvements in their social skills, given that they had managed to expand their group of friends and improve their relationship with them.

Now I know kids in every class, I know almost everyone (...) (people in my family) tell me I'm more sociable, I talk more now. (Pablo, 14-year-old male)

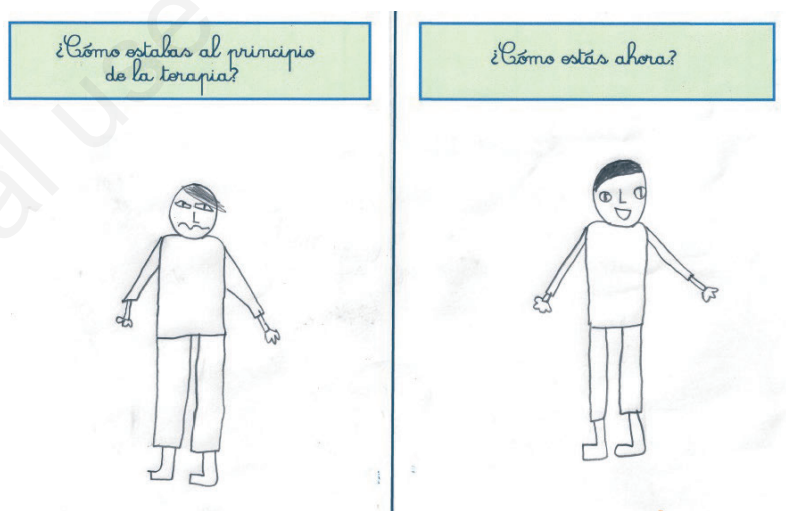

Figure 1. Before and now drawing by Vicente, a 7-year-old boy.

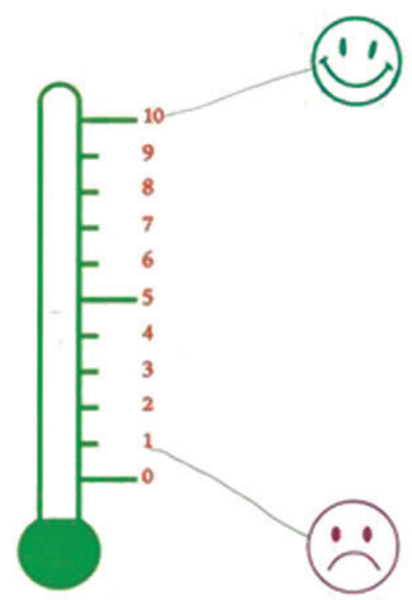

Figure 2. Thermometer completed by Paloma, a 7-year-old girl. 


\section{Self- and growth-related changes}

The participants described changes in their self-concept, including more self-confidence and more self- acceptance. They also reported identity-related changes, noting that they feel better people and that they used to be different.

Their idea of change can be said to be linked to growth: it involves not only a maturation processes and becoming older, but also physical changes, such as feeling taller and bigger and looking different. This can also be observed in the participants' drawings. They included smaller human figures at the start of the process, which became bigger in the current moment of the therapy, thus reflecting a concrete perception of growth, as shown in Figure 3.

\section{Behavioral, cognitive, and school-related changes}

The participants' narratives, to a lesser extent, also reflected a change related to cognitive elements. These changes are mainly related to the way of thinking about themselves and environmental events, highlighting their increased reflective skills and flexibility in their thinking. This is mainly observed in adolescents or older children. In addition, the interviewees reported a greater ability to understand their social and family environment and to have the skills to solve problems differently to how they would approach them before the psychotherapy process.

It was also like rehearsing everything about myself, 'why are you feeling low? why are things going badly? and, no! you did this wrong, so you must try to do it better next time, and if it's better that'll help you do better at school' [...] so one gets a different perspective to improve all that. (Patricia, 16-year-old female)

In addition, the participants noted behavioral changes: they saw themselves as more obedient and helpful indi-

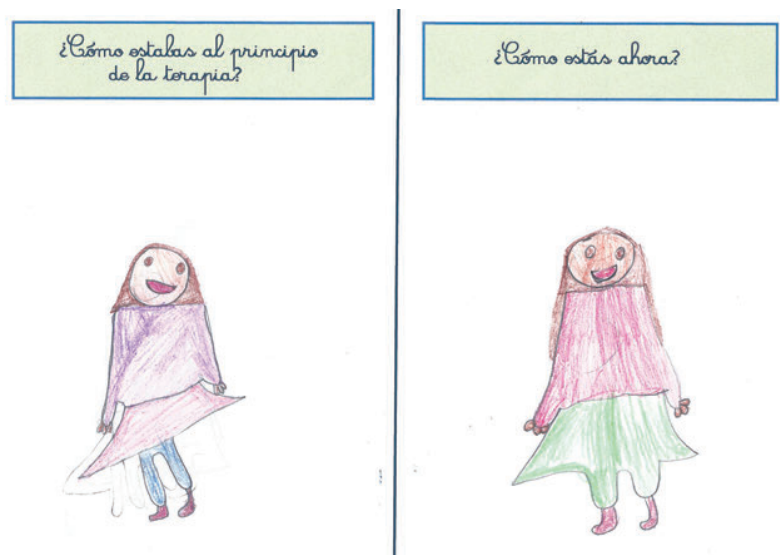

Figure 3. Before and now drawing by Bárbara, a 6-year-old girl. viduals, also managing to resume activities that they had abandoned. In some cases, these changes led to further changes in school which, apart from behavioral improvements, included better academic performance, which in turn resulted in a perception of well-being in this context.

I have better marks now (at school). (Isabel, 10year-old-girl)

My teacher told me I'm better behaved in class now and that I'm responding better. (Celeste, 9-yearold child)

\section{Changes linked to the abusive experience}

Only some participants, mainly adolescents, mentioned in the interviews that even though some effects of the sexual abuse suffered still remain, they have experienced emotional relief and tranquility regarding the negative events, stating that they feel less guilt, embarrassment, sadness, and emotional pain when talking about or remembering the subject.

They also noted that their thoughts about the abusive experience are less recurrent. However, some developmental differences between the participants can be observed: the adolescents mentioned that although they had not forgotten the sexual abuse, it had become less and less present in their everyday memories, while the children stated that they wished they could forget their problems or the negative situations that had occurred.

(Therapy) helps me forget faster, it's like I'm: no, I'm not so interested in that issue now - it helps me focus on other things (...) not making such a big deal of it has helped me a little, it's like I'm not embarrassed to talk about it anymore. (Pablo, 14-year-old male)

In only one case the participant reported healing from the abusive experience. In this case, the adolescent's narrative was structured around the notion that abuse is a negative experience that cannot be forgotten, but that life can go on and one can stand up again. In this specific case, the idea of leaving the problem behind was also manifested through the participant's new life plans and goals.

It's like I left that stage of my life in the past, now I understand that it's gone, that I can't erase it, but I can live with it (...) I don't look back anymore, I don't focus on the past, I pay attention to my present and my future. (Patricia, 16-year-old female)

It should be noted that this is the only patient in the sample who had experienced one abusive episode, by someone outside her family. She was the oldest participant and the only one who had previously received mental health treatment.

One of the participants also mentioned changes in terms 
of protection, as measures had been taken which led to a safer and violence-free environment and to a restraining order for the attacker, which made him feel calm and safe.

\section{Changes in attitude towards the therapy}

Most participants had initially resisted entering the therapeutic space, they showed low interest in going to therapy; in addition, they portrayed feelings of nervousness, mistrust, boredom, and a lack of knowledge about this new environment. The interviewees displayed changes in their attitude towards therapy, as their interest in participating grew and their fears or negative emotions towards this space decreased over the course of the process. They became more trustful and accustomed to the therapy.

\section{I: What did you imagine before coming to therapy at this center? \\ P: That's how I felt, I mean, it was far away, I didn't want to come, but now I want to come \\ I: Oh, okay, why did you change your mind? \\ P: Because I got used to it. (Isabel, 10-year-old girl)}

The above can also be observed in some drawings, such as the one in Figure 4, in which the child expresses this through her visual and written narrative. At the beginning of the therapy, her lack of motivation regarding this space was shown through words commonly used by adolescents to denote a lack of interest. However, in the drawing representing the present state of the therapy, she displays much more motivation through her bodily, facial, and written attitude.

Narrative of the pre-therapy drawing: I mean, it was a drag coming here (...) and being asked questions it was like: 'why am I gonna go if I won't open up to anyone'.

Narrative of the drawing representing the current state of the therapy: Now I'm like: it's Wednesday at last (...) I

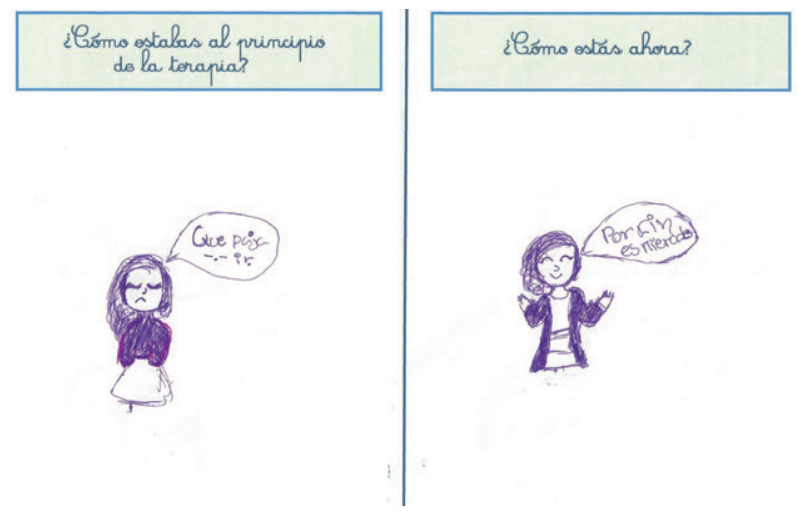

Figure 4. Before and now drawing by Aurora, an 11-year-old girl (the drawing said in the left hand side What a drag!, and in the other side It's Wednesday at last!). kind of enjoy coming here, I like it but I didn't like it before (...) now I trust the psychologist and I'm here. (Aurora, 11-year-old girl)

\section{Changes in the participants' parents}

The participants stated that over the course of the therapy, they have noticed positive changes in their parents or adult caregivers. They see these changes mainly in their maternal figures, who are described as being more loving and attentive, as well as less hostile. In addition, the participants noted that their maternal figures feel more relaxed when they see that their children feel better.

\section{I: You were saying that your mom has also changed \\ P: Yes \\ I: How can you see that? \\ P: In her attitude towards me, because she used to be much more annoying [...] she's changed too. (Au- rora, 11-year-old girl)}

Two participants described changes in their parental couple, noting that they look stronger, argue and fight less often, and reach agreements to go together to therapy. In one case, the parental change observed was described in a predominantly negative way, as the participant considered her parents to be extremely overprotective.

\section{How does it change?}

\section{Gradual change}

The participants' narratives suggest that they conceptualize change as a process, since they convey the idea that it is progressive and does not happen suddenly. Thus, they reported that feeling better is mediated by the passage of time and that well-being is attained gradually.

It happened after some time, because nothing happens overnight, that's for sure, but after some time I kind of left that anger behind. (Patricia, 16-year-old female)

\section{Pending changes and projected future changes}

Despite all the changes mentioned by the participants, they were also able to reflect on things that they have yet to modify.

\section{I'm still stubborn. (Denise, 9-year-old girl)}

The participants reported situations that they hoped would change in the future, such as feeling even better than at present. This expectation was mainly expressed thanks to the use of the thermometer, through which the interviewees rated their present state as better than at the beginning of the therapy, but voiced the desire to feel better at the end of the process. 
I: How sad or how happy were you when you started coming to therapy?

P: Let's see...I was like a three or four.

I: Three or four, okay, and how are you now?

P: A five, six, or seven (laughs)

I: Okay, and how would you like to feel at the end of the therapy?

P: Um, a ten?

I: A ten...so, you've been feeling better but you'd like to feel even better

P: Yes! (Trinidad, 14-year-old female)

Expectations of future change referred both to the ability to overcome the sexual abuse experience and to other aspects of life, including personal goals such as going to university and having a professional career.

I want, one day I dreamed I was in college (...) and I wanted to be a designer or a singer or a skater. (Celeste, 9-year-old girl)

\section{What remains}

In this permanent process of change, the interviewees also noted that some elements remain unchanged over time, such as their personality, which is felt to provide them with a sense of continuity.

I: Is there something else you feel has changed in you after all this time?

P: Um, I don't know, I've always been the same way I'm now.

I: Okay.

P: It's just that there was a time when I-I felt low [...] not anymore, that's changed. (Trinidad, 14-yearold female)

This can also be observed graphically, as the before/now drawings produced by some patients reveal the persistence of certain graphic traits in both drawings, which display common elements such as their physical organization or the colors used (Figure 1).

\section{Factors that foster and hinder change}

\section{Psychotherapy}

Psychotherapy was highlighted as an essential, change-fostering factor. Within psychotherapy, talking with the psychologist is identified as a factor that facilitates change. Also, the opportunity to play and laugh in this context is believed to help to forget the abusive experience. Play activities in therapy are specially highlighted by younger children.

All I know is that when I come here, there are times when I'm feeling down but talking with the psychologist makes me feel better, it's like I get something off my chest, it's like it lets me share things with someone. (Trinidad, 14-year-old female)

The patient-therapist relationship was one aspect of the therapy considered to foster change. The participants reported having a trust-based relationship with the psychologist, given that they were able to speak their mind, vented their problems, and received help from the professional. Therapists were considered as people who helped them reflect on their actions and who participated in the change process.

(My relationship with the therapist) is good, because: we tell each other a lot of stuff, she's like my diary. (Celeste, 9-year-old girl)

She's also helped me like in the way I think [...] that: I mean lately the psychologist has helped me reflect on things I've done, so I take that as an example: and I change things based on that (laughs). (Aurora, 11-year-old girl)

The use of multiple techniques during the therapy is also highlighted as an element that fosters change.

We also laugh a lot, um: let's see...we talk a lot, we play, a lot, we draw a lot. (Paloma, 7-year-old girl)

However, some elements of the psychotherapy appear to hinder change, the most relevant being therapist changes. In most cases, during the psychotherapeutic processes, therapists were switched for various reasons, including workplace changes and staff rotation at the centers that the participants attended, among other factors.

These therapist changes are, in general, negatively viewed by the participants. Their reasons include sadness to lose the first therapist, having to spend some time without an intervention, or preferring the original therapist and his/her activities.

Nevertheless, despite this negative assessment, the participants noted that even though this may have affected their process, they adapted to the situation, overcame their initial anxiety, and established positive bonds with the new therapists.

\footnotetext{
I: And how did you feel when your psychologist was changed?

P....Sad (it had an effect on the therapy) [...] (but) then the therapist [I have now] um I reconciled with her little by little and I didn't feel sad anymore. (Vicente, 7-year-old boy)
}

In two cases, the therapist change did not appear to affect the process in any major way. In both, the replacement took place at the beginning of the therapy, which may have eased the transition. 
(Regarding the effects of the therapist replacement) no, it didn't have a big impact, if I'd had many sessions with Ms. D. I think it would've had an influence, but it didn't (Patricia, 16-year-old female)

\section{Family support}

The support received from several family members was mentioned as a relevant change-promoting element. The participants noted that spending time with their family and having a loving relationship with their siblings helped them in this regard. One of the key change-promoting aspects mentioned by some participants is family support with respect to the therapeutic process, in addition to the encouraging messages received from this nucleus.

(How family has helped) they've supported me, they say 'you're doing the right thing, you have to stay on the right track' and also come to therapy often. (Pablo, 14-year-old male)

The support received from the maternal figure and the bond established with her emerges as a particularly relevant element.

Well, I don't know, it's like she always, well my mom when I'm sad she tells me 'get up and go!' and my mom is like, I don't know, very active, cheerful. (Trinidad, 14-year-old female)

In contrast, a lack of family support is described as an element that hinders change. Specifically, in one case included in the sample, this lack of support is linked to doubts regarding the occurrence of the sexual abuse by a family member. This is experienced by the participant as a lack of trust in her, which is singled out as a fundamental factor that makes psychotherapeutic change more difficult.

(What makes change harder) my brother didn't believe me [...] (I felt) bad, because he thought that what happened to me was a lie [...] it feels awful because I don't know, I feel he doesn't trust me. (Trinidad, 14year-old female)

\section{Support from people outside the family}

Having a support network outside the family was mentioned as a relevant factor for facilitating change. The participants singled out friends as important people for them, highlighting that being able to have fun and play with a peer group generates well-being, helping them to forget the sexual abuse and reduce its presence in their everyday lives.

(With respect to school support) the teacher said 'something bad happened to Paloma, so don't upset her' and then my classmates got closer to me: they sthey say 'okay! forget about those things and let's play hide-and-seek, ring-a-ring-a-roses', those are the games we play. (Paloma, 7-year-old girl)

Not only the peer group and the school emerge as a relevant support network: having pets is another factor that appears to facilitate change in children and adolescents.

And when I got my little dog it was like, it w-, I felt better because I felt that the dog, if I was sad, he felt I was sad and kept me company (...) (Trinidad, 14year-old female)

\section{Personal factors}

The participant who stated that she had already healed from the sexual abuse, mentioned certain personal aspects that seemed to have facilitated the change process. She noted that believing in the possibility of feeling better and making personal efforts to achieve this goal had helped her in her change process. In addition, she identified some personal strategies that she used in order to tackle down the difficulties present in this process, for instance, fears and traumatic memories.

Ifeel it was fifty-fifty, the therapist did one half and I did the other, because you need to take charge, it's worthless to come here to the psychologist's office and tell him things if I know I'm not gonna get better, if I'm gonna stay the same, first you have to know yourself and face your fears, your worries. (Patricia, 16year-old female)

\section{Judicial factors}

In one of the cases, the participant's relationship with the judicial system emerged as a powerful factor that hinders change. The judicial system affects the process mainly because the patients expect penal proceedings to progress and result in a sentence for their attacker. Since this is not often the case, their perception of the system is negative: it is considered as inefficient, while legal proceedings are slow and tiring.

So I feel justice doesn't really support victims and making an accusation for something like this can be irritating. (Patricia, 16-year-old female)

\section{Discussion and Conclusions}

The results of this article about therapeutic change during initial or intermediate stages of therapy in children and adolescents who have been sexually abused, revealed changes in multiple developmental areas, especially in the emotional sphere. In a recent study on change in child psychotherapy, which considered multiple reasons for seeking help, Alamo et al. (2016) also found that change 
involves several dimensions similar to those identified here. However, in the present study, given the specific population examined, certain changes linked to the abusive experience emerged. Moreover, this highlights the idea, also pointed out by Di Riso, Gennaro and Salcuni (2015), that change in psychotherapy goes beyond symptom remission.

According to Krause et al. (2006), the content of change is subjective, thus it is linked to self-representation and the perso's relationships with his/her environment. In the present study, this can be observed in the participants' identification of several elements, including changes in their view of themselves, such as increased trust in themselves (self-concept changes) and growth-related changes. At the same time, they point out that some elements of their selves remain and give them a sense of continuity. Phillips and Daniluk (2004) have also reported changes in self-definition and self-acceptance in sexually abused women at the end of the treatment.

In addition, the participants conceptualized change as gradual, and even though they observed several changed aspects, they acknowledged that some changes remain incomplete and they expect to improve even more in the future. In relation to the evolution of change, Krause et al. (2006) suggested that changes are successive and are based on previous ones, subsuming them. This notion of gradual change has been shown in several studies (Echavarri et al., 2009; Fernandez et al., 2015; Gonçalves et al., 2009) and can also be observed when comparing the results of the present study, which analyzed the views of patients regarding psychotherapeutic changes in the initial and middle stages of the therapy, with other studies focusing on other stages of the process. For example, a previous study by Capella et al. (2016), presented the results of 20 interviewed children and adolescents who were completing or had completed a therapy process due to sexual abuse. The participants noted that they had gone through a process during which they gradually healed from sexual abuse, which they described as ongoing, positive, and involving personal growth.

In this study, Capella et al. (2016) found that patients interviewed towards the end of the therapy stated that they had healed from the abuse suffered, which they regarded as an achievement resulting from personal efforts, although they also acknowledged the presence of a context that fostered their recovery. In contrast, the present study found that only a minority of patients in the initial and middle stages of the therapy mentioned early changes related to the sexual abuse, without noting deeper changes linked to healing from the experience. Most of these cases were adolescents, which can also be related to developmental resources for elaboration of the abusive experience and the capacity to express this elaborative process during the interview.

Notwithstanding, at the beginning of the therapy, patients consistently reported affective changes, mainly linked to symptomatological remission and a greater feeling of well-being. Based on this observation, it can be presumed that the first stage in the therapeutic change process is linked precisely to these emotional changes that make possible to get a feeling of general well-being, and that once this state is attained, it is possible for the person to advance in the therapeutic process and eventually elaborate the trauma. This may be related to what has been reported in the literature which states that change occurs in several phases within the therapy (Águila et al., 2016; Altimir et al., 2010; Echavarri et al., 2009; Krause, 2005; Krause et al., 2006), and may point out that the patients in this sample are in an initial or middle phases of therapy, related to the theoretical proposal of Gomez (2016).

Even though there is limited literature, the available evidence allow to hypothesize that emotional relief is one of the first changes in these cases. For instance, Jessiman et al. (2017) studied children and adolescents who experienced sexual abuse and who recently completed a therapeutic intervention (between 6 and 30 sessions long) to address said experience. These investigation found that the psychotherapeutic process with children and adolescents helped them to feel emotional relief, a fact that was highlighted both by the participants and their caregivers. In this study, the children tended to self-report as happier at present. Even though Jessiman's study examined children who completed their therapy, the number of sessions that they attended roughly matched the moment when the interviews were conducted in the present study (between 14 and 26 sessions). That is, what was defined as the initial or middle stage of the therapy in the present study was the final stage of the intervention for Jessiman et al. (2017), with both processes including a similar number of sessions. Despite these differences in the understanding/categorization of the intervention, emotional relief emerged as a relevant change for both samples at similar moments.

This could be explained in relation to an article by Beiza et al. (2015), who states that different narrative positions exist with respect to the healing process from sexual abuse. On the one hand, this study examined cases with an incipient healing narrative in which some changes can be observed, certain negative consequences of the abuse still linger and make it difficult for the victims to resignify the traumatic experience and integrate it into their life continuum. If this concept is linked to the present study, it could be hypothesized that this is what occurs in the initial stages of therapy: even though positive changes are identified in comparison to past moments, they do not involve the elaboration of the abusive experience. On the other hand, the final moments of the therapy process studied by Capella et al. (2016) could be linked to a second narrative position proposed by Beiza et al. (2015), which the authors label as healing narratives. Such narratives are characterized by the attribution of new meanings to the abusive experience and its integration into one's per- 
sonal history through a dynamic process of growth and change. These aspects have also been highlighted by previous authors as healing from abuse, which is a dynamic process (Banyard \& Williams, 2007; Draucker et al., 2011; Harvey et al., 2000).

As noted in the results section, one of the participants of the study displayed healing narratives. The participant referred to the concept of healing, stressing the importance of personal factors for achieving it. In addition, this interviewee alluded to judicial proceedings as a barrier to healing from abuse. All these elements are similar to those found by Capella et al. (2016) in patients who completed their therapy. This particular case may be understood considering its specific characteristics. She was the oldest patient in the sample (16 years old), and this fact may have allowed her to analyze the therapy more reflectively. In addition, it was the only case included in which the perpetrator was a non-relative who had attacked the victim only once. These characteristics may have produced differences in the process of therapeutic change and healing from the negative event, because they could have configured a different traumatic experience from that of the other participants. In this regard, several factors have been described which have an impact on the consequences of sexual abuse, including the victim's relationship with the perpetrator, the chronicity of the abuse, and the victim's age (Echeburúa \& Corral, 2006). Also, this participant had taken part in previous mental health interventions, which means that her change and overcoming process may have started before her psychotherapy at the specialized center included in this study.

Even though most of this patient's narrative reflects healing from sexual abuse, some remaining traumatic elements still require to be elaborated. Specifically, the participant expressed a deep conflict with the judicial system. This finding is in line with the literature (Capella et al., 2016; Foster \& Hagedorn, 2014; Lama et al., 2015), which reveals that victims of sexual abuse have a problematic relation with the legal system. Consistently with those studies this participant manifested feelings of frustration and described her passage through the judicial systems as long and difficult. In her case, the judicial inquiry has not been successful, and like in the cases examined by Foster and Hagedorn (2014), the victim's narratives revealed a strong feeling of injustice. In addition, in other studies (Foster \& Hagedorn, 2014; Lama et al., 2015) participants reported secondary victimization situations such has having to narrate the traumatic events repeatedly. The similarity between national and international results highlights the importance of improving the implementation of legal proceedings in cases involving children and adolescents.

Alongside this legal factor, which is identified as a barrier to change, the participants also mentioned changehindering elements such as the fact that their family do not believe them and fail to support them, as well as therapist changes. Other facilitating factors include the pa- tient-therapist relationship, the use of multiple techniques in the therapy, family support, and social support. Younger children highlight especially the use of play in therapy, which can be understood as an important age-related activity. Some of these factors are similar to those reported in other studies (Banyard \& Williams, 2007; Draucker et al., 2011; Gomez, 2016; Harvey et al. 2000; Saha et al, 2011). Thus, from the participants' perspective, several factors appear to influence the change process in psychotherapy. This suggests that even though therapy is a fundamental factor for attaining change, not all the changes displayed by the participants can be attributed to it. It is also especially important to highlight familiar factors as hindering or favoring change, considering that most of the participants were abused by family members. In intra-familiar abuse, it has been described that the family dynamics tend to divide or conflict the family and their relations (Barudy, 1998). In this context, support from family members could help children and adolescents feel validated and believed, and this could help in their change process. When they are not believed, this could make them feel confused in the family dynamics and make the change process more difficult.

Along with these factors mentioned by the participants and the notion of change as a gradual process that happens over time, it is important to add a developmental perspective, which is fundamental in child and adolescent psychotherapy (Sepúlveda, 2013). Thus, since children are undergoing a developmental process, the change process in child and adolescent psychotherapy is presumably influenced by this developmental process. This aspect should be examined in more depth in studies on change in child and adolescent psychotherapy. Also, we can see in this study that even though change is similar in the children and adolescents from this study; there are some differences related specially to changes that involve more reflexive capacities, like cognitive changes or elaboration of the abuse.

Among change-facilitating factors, the participants highlighted their trust- and acceptance-based relationship with the therapist. A positive therapist-patient relation is an aspect that has been widely described in psychotherapy research as an element that influences psychotherapy outcomes (Fernandez et al., 2016; Horvath, Del Re, Flückiger, \& Symonds, 2011). Similar results are also reported by Jessiman et al. (2017) in populations of sexual abuse victims. These researchers found that the child-therapist relationship was valued by both the children and their parents as a relevant part of the intervention experience. In the present study, as well as in Jessiman et al. (2017), children valued the chance to talk to an understanding and supportive person with whom they developed a trustbased relationship that allowed them to discuss difficult issues, but who also gave them the freedom to not talk about uncomfortable subjects. In addition, the therapist is cosnidered as an agent who fosters the patient's reflection 
and takes part in his/her change. Likewise, both studies reported that the techniques used in the intervention facilitated change and that their diversity allowed children to get involved in the therapeutic process.

Finally, it must be noted that family support is a facilitator of change, which can be observed both in support in everyday life and in the specific context of psychotherapy, for example, going with children to sessions. Also, in this study, barriers for change include not being believed by others and not receiving support. These elements are also underlined in international studies. For example, in a study with girls who had been sexually abused, Nelson-Gardell (2001) found that one of the most important issues for the participants was their equating of being believed with receiving help. In contrast, not being believed was perceived as unhelpful or even damaging factor. These results stress the importance of the first reactions to the disclosure of sexual abuse, especially when the attackers are parents or close relatives.

With respect to parents, a novel result is that the participants also perceived changes in their parents or caregivers, which is in line with the findings reported by Alamo et al. (2016). This highlights the relevance of studying in more depth the inclusion of parents in their children's psychotherapy, as well as the importance of examining their views comprehensively in order to integrate them as active participants in their children's change process.

One of the main contributions of this study concerns the methodology used. As in other studies (Capella et al., 2015; Carlberg et al., 2009), innovative nonverbal information collection techniques were used, including before/now drawings and the visual support technique thermometer to facilitate the expression of feelings and thoughts during the interview taking into account the participants' developmental abilities. In this regard, the use of said techniques is believed to enable children to express feelings and thoughts in a more comfortable and natural manner, especially for the younger ones.

In line with Carlberg et al. (2009), in the present study the participants easily understood the use of the thermometer as a rating instrument and used the drawings as a way to express themselves. These instruments allowed them to convey experiences and feelings, while also helping them to complement their verbal narratives. It must be pointed out that some elements of change only appeared in the participants' drawings, while others were only expressed verbally; therefore, they can be considered as complementary techniques (Capella et al., 2015). To sum up, it can be stated that consistently with the literature, the present study sheds light on how children experience psychotherapy (Carlberg et al., 2009; Caroll, 2002; Stith, et al., 1996).

Apart from its methodological innovations, this study makes other contributions. First, it examines therapeutic processes as they occur. Thus, it revealed that patients are able to report their own therapy processes while they are conducted, which highlights the self-reflective skills of child and adolescent patients. This is consistent with Carlberg et al. (2009), who suggests that it is possible to gain access to children's experiences in psychotherapy by using alternative research methodologies beyond the purely verbal.

Additionally, the interviews conducted did not cause any difficulties to the patients, nor did they interrupt their processes. This was mainly since all ethical and research design safeguards were adopted to avoid disrupting the patients' therapy processes. In order to achieve this, the researchers worked directly with the therapists to conduct the interviews at times when they would be as innocuous as possible for the patients and in a setting resembling the clinical one, which was expected to be less threatening. In addition, the interviews were conducted by professionals trained in clinical work with children and adolescents, which also made it possible to safeguard the participants' well-being.

Thus, one of the main contributions of this study is that it collects the experiences of children and adolescents as protagonists of their recovery from sexual abuse. As Nelson-Gardell (2001) points out, few qualitative studies considered children's and adolescents' personal accounts of change processes after sexual abuse experiences.

These studies allow us to identify, based on children's and adolescents' own perspectives, their needs during each stage of the therapy process, which could shed light on the multiple strategies that we should strengthen in various moments of the psychotherapy to foster psychotherapeutic change.

However, as a limitation of the study is that it only includes the view of the children and adolescents, and to have a more comprehensive view of psychotherapeutic change, it would be necessary in future studies to complement it with the views of other relevant participants of psychotherapy, such as their parents and therapists.

Also, another limitation is that just a few cases were examined; therefore, we need to understand the results of this study as preliminary. This makes it impossible to establish deeper distinctions between elements that may eventually influence the participants' views on psychotherapeutic change, such as developmental differences and the types of aggression experienced, among other elements.

Based on the results, some ideas may be derived regarding the intervention length necessary in these cases. The patients included in this study received therapy between 6 and 9 months, however, they are considered to be in the initial or middle stage of the process. This makes sense when the interviews were analyzed. Despite the several changes reported by the participants at this point of the psychotherapeutic process, there are some areas that still need to be worked through, particularly those related with the elaboration of the sexual abuse. 
Thus, based on the results reported, it is also possible to assert that longer interventions are needed for the therapy to develop and for the necessary changes to occur in these cases. This situation poses challenges for new studies, which could analyze the moments of the therapy in which changes linked to abuse elaboration are hosted. The relevance of this is related to the objectives proposed for therapy in these cases, related with giving new meanings to the traumatic experience (Capella \& Gutierrez, 2014; Neimeyer et al., 2006; Ronen, 1996).

Finally, future studies on this topic should also include follow-up mechanisms for patients in several moments of the intervention to study psychotherapeutic change longitudinally, as it happens, until the final phases of the psychotherapy are reached. This type of study should help generate better guidelines for conducting psychotherapeutic processes with sexually abused children.

\section{References}

Águila, D., Lama, X., Capella, C., Rodríguez, L., Dussert, D., Gutiérrez, C., \& Beiza, G. (2016). Narratives from therapists regarding the process of psychotherapeutic change in children and adolescents who have been victims of sexual abuse. Studies in Psychology, 37, 344-364. doi: 10.1080/02109395. 2016.1204780

Alamo, N., Capella, C., Nuñez, L. \& Krause, M. (2016). What changes during psychotherapeutic process with children? A qualitative approach from the perspective of therapists, children and family members. Paper presented at 47th SPR International Annual Meeting. 22-25 June 2016, Jerusalem, Israel.

Altimir, C., Krause, M., De la Parra, G., Dagnino, P., Tomicic, A., Valdés, N. et al. (2010). Clients', therapists', and observers' agreement on the amount, temporal location, and content of psychotherapeutic change and its relation to outcome. Psychotherapy Research: Journal of the Society for Psychotherapy Research, 20, 472-487.

Banyard, V., \& Williams, L. (2007). Women's voices on recovery: A multi-method study of the complexity of recovery from child sexual abuse. Child Abuse \& Neglect, 31, 275 290.

Barudy, J. (1998). El dolor invisible en la infancia [The invisible pain during childhood]. Buenos Aires, Argentina: Paidós.

Beiza, G., Capella, C., Dussert, D., Rodríguez, L., Águila, D., Gutiérrez, C., \& Lama, X. (2015). Institutionalized adolescents in therapy: Narratives toward psychotherapy and healing from sexual abuse experiences. Research in Psychotherapy: Psychopathology, Process and Outcome, 18, 62-71.

Binder, P., Moltu, C., Hummelsund, D., Sagen., S \& Holgersen, H. (2011). Meeting an adult ally on the way out into the world: Adolescent patients' experiences of useful psychotherapeutic ways of working at an age when independence really matters. Psychotherapy Research, 21, 554-566.

Bradding, A., \& Horstman, M. (1999). Using the draw and write technique with children. European Journal of Oncology Nursing, 3, 170-175.

Bury, C., Raval, H. \& Lyon, L. (2007). Young people's experiences of individual psychoanalytic psychotherapy. Psychol- ogy and Psychotherapy: Theory, Research and Practice, 80, 79-96.

Cantón, J. \& Cortés, M. (2004). Malos tratos y abuso sexual infantil [Maltreatment and child sexual abuse]. Madrid: Editorial Siglo XXI.

Capella, C. \& Gutiérrez, C. (2014). Psicoterapia con niños/as y adolescentes que han sido víctimas de agresiones sexuales: Sobre la reparación, la resignificación y la superación. [Psychotherapy with children and adolescents that have been victims of sexual abuse: Toward repairing, resignification and healing]. Psicoperspectivas, 13, 93-105.

Capella, C. (2011). Hacia narrativas de superación: El desafío para la psicoterapia con adolescents de integrar la experiencia de agresión sexual a la identidad personal [Towards narratives of healing: The challenge for adolescents psychotherapy to integrate the experience of sexual assault to personal identity] (doctoral thesis). Universidad de Chile, Santiago, Chile.

Capella, C., Lama, X., Rodríguez, L., Águila, D., Beiza, G., Dussert, D. \& Gutiérrez, C. (2016). Winning a race: Narratives of healing and psychotherapy in children and adolescents who have been sexually abused. Journal of Child Sexual Abuse, 25, 73-92.

Capella, C., Rodríguez, L., Águila, D., Dussert, D., Lama, X., Gutiérrez, C., \& Beiza, G. (2015). Storied images of psychotherapeutic change: Approaching children's voices through drawings. Research in Psychotherapy: Psychopathology, Process and Outcome, 18, 141-151.

Carlberg, G. (1997). Laughter opens the door: turning points in child psychotherapy. Journal of Child Psychotherapy, 23, 331-349.

Carlberg, G., Thoren, A., Billström, S., \& Odhammar, F. (2009). Children's expectations and experiences of psychodynamic child psychotherapy. Journal of Child Psychotherapy, 35, $175-193$.

Carroll, J. (2002). Play therapy: the children's views. Child and Family Social Work, 7, 177-187.

Centro de Asistencia a Víctimas de Atentados Sexuales [CAVAS] (2011). Centro de Asistencia a Víctimas de Atentados Sexuales: Una revisión de la experiencia [Center for Assistance of Sexual Abuse Victims, Metropolitan CAVAS: a review of experience]. Santiago: Instituto de Criminología, Policía de Investigaciones de Chile.

Di Riso, D., Gennaro, A., \& Salcuni, S. (2015). Defensive mechanisms and personality structure in an early adolescent boy: Process and outcome issues in a non-intensive psychoanalytically oriented psychotherapy. Research in Psychotherapy: Psychopathology, Process and Outcome, 18, 114-128.

Draucker, C. B., Martsolf, D., Roller, C., Knapik, G., Ross, R., \& Stidham, A. (2011). Healing from childhood sexual abuse: A theoretical model. Journal of Child Sexual Abuse, 20, 435466.

Driessnacks, M. (2005). Children's drawings as facilitation of communication: A meta-analysis. Journal of Paediatric Nursing, 20, 415-422.

Echávarri, O., Gonzalez, A., Krause, M., Tomicic, A., Perez, C., Dagnino, P., De la Parra, G., Valdés, N., Altimir, C., Vilches, O., Stasser, K., Ramirez, I. \& Reyes, L. (2009). Cuatro terapias psicodinámicas breves exitosas estudiadas a través de los indicadores genéricos de cambio [Four successful brief psychodynamic therapies studied through generic change indicators]. Revista argentina de Clínica Psicológica, 28, 5-19.

Echeburúa, E \& Corral, P. (2006). Secuelas emocionales en víc- 
timas de abuso sexual en la infancia [Emotional aftermath on childhood sexual abuse victims]. Cuadernos de Medicina Forense, 12, 43-44.

Elliott, R. (2008). Research on client experiences of therapy: introduction to the special section. Psychotherapy Research: Journal of the Society for Psychotherapy Research, 18, 239242.

Fernández, O. (2013). Alianza terapéutica, acciones comunicacionales e indicadores de cambio genéricos en la fase inicial de la psicoterapia con adolescentes, y su relación con resultados y adherencia al tratamiento [Therapeutic Alliance, comunicative actions and generic change indicators in the initial phase of psychotherapy with adolescentes, and their relation with the outcomes and adherece to the treatment] (doctoral thesis). Pontifica Universidad Católica de Chile, Santiago, Chile.

Fernández, O., Krause, M., \& Pérez, J. (2016). Therapeutic alliance in the initial phase of psychotherapy with adolescents: different perspectives and their association with therapeutic outcomes. Research in Psychotherapy: Psychopathology, Process and Outcome, 19, 1-9.

Fernández, O., Pérez, J., Glober, S., \& Krause, M. (2015). Relevance of early changes in psychotherapy with adolescents. Terapia Psicológica, 33, 247-255.

Foster, J. \& Hagedorn, B. (2014). Through the eyes of the wounded: A narrative analysis of children's sexual abuse experiences and recovery process. Journal of Child Sexual Abuse, 23, 538-557.

Gibson. K., \& Cartwright, C. (2014).Young clients' narratives of the purpose and outcome of counselling. British Journal of Guidance \& Counselling, 42, 511-524.

Gil, E. (2006). Helping abused and traumatized children: Integrating directive and nondirective approaches. New York: The Guilford Press.

Gómez, C. (2016). Cambio psicoterapéutico en niños, niñas y adolescentes que han sido víctimas de agresiones sexuales: Una aproximación y propuesta teórica [Pychotherapeutic change in children and adolescentes that have been victims of sexual abuse: An approximation and theorical proposal] (undergraduate thesis). Universidad de Chile, Santiago, Chile.

Gonçalves, M. M., Matos, M. \& Santos, A. (2009). Narrative therapy and the nature of 'innovative moments' in the construction of change. Journal of Constructivist Psychology, $22,1-23$.

Harvey, M., Mishler, E., Koenen, K., \& Harney, P. (2000). In the aftermath of sexual abuse: Making and remarking meaning in narratives of trauma and recovery. Narrative Inquiry, 10, 291-311.

Heinzel, F. (1997). Qualitative Interviews mit Kindern. In Barbara Friebertshäuser \& Annedore Prengel (Eds.), Handbuch Qualitative Forschungsmethoden in der Erziehungswissenschaft (pp. 396-413). Weinheim, München: Juventa.

Hetzel-Riggin, M., Brausch, A. \& Montgomery, B. (2007). A meta-analytic investigation of therapy modality outcomes for sexually abused children and adolescents: An exploratory study. Child Abuse \& Neglect, 31, 125-141.

Horvath, A., Del Re, A., Flückiger, C., \& Symonds, D. (2011). Alliance in Individual Psychotherapy. Psychotherapy, 48, 916.

Jessiman, P., Hackett, S. \& Carpenter, J. (2017). Children's and carers perspectives of a therapeutic intervention for children affected by sexual abuse. Child \& Family Social Work, 22, 1024-1033.
Krause, M. (2005). Psicoterapia y cambio. Una mirada desde la subjetividad [Change and psychotherapy. A look from the subjetivity]. Santiago, Chile: Ediciones Universidad Católica.

Krause, M., Parra, G., Arístegui, R., Dagnino, P., Tomicic, A., Valdés, N. et al. (2006). Indicadores genéricos de cambio en el proceso psicoterapéutico. Revista Latinoamericana de Psicología, 38, 299-325.

Kuhn, P. (2003). Thematic Drawing and Focused, Episodic Interview upon the Drawing: A Method in Order to Approach to the Children's Point of View on Movement, Play and Sports at School. Forum Qualitative Sozialforschung/Forum: Qualitative Social Research, 4, Art. 8. Available from: http://nbnresolving.de/urn:nbn:de:0114-fqs030187.

Lama, X., Gutiérrez, C., Capella, C., Dussert, D., Rodríguez, L., Beiza, G. \& Águila, D. (2015). Superación de agresiones sexuales infanto-juveniles y el sistema judicial: Una visión desde los participantes [Healing from child and youth sexual assault and the justice system: A view from the participants]. Revista de Psicología, 24, 1-19.

Llanos, M.T. \& Sinclair, C. (2001). Terapia de reparación en víctimas de abuso sexual: Aspectos fundamentals [Therapy with victims of sexual assault: Fundamental topics]. Psykhe, $10,53-70$.

Malacrea, M. (2000). Trauma y reparación: El tratamiento del abuso sexual en la infancia [Trauma and reparation: treatment of sexual abuse during childhood]. Barcelona: Paidós.

Midgley, N. (2004). Sailing between Scylla and Charybdis: Incorporating qualitative approaches into child psychotherapy research. Journal of Child Psychotherapy, 30, 89-111.

Midgley, N., Target, M. \& Smith, J. (2006). The outcome of child psychoanalysis from the patient's point of view: A qualitative analysis of a long-term follow-up study. Psychology and Psychotherapy: Theory, Research and Practice, 79, 257-269.

Neimeyer, R., Herrero, O., \& Botella, 1. (2006). Chaos to coherence: Psychotherapeutic integration of traumatic loss. Journal of Constructivist Psychology, 19, 127-145.

Nelson-Gardell, D. (2001). The voices of victims: Surviving child sexual abuse. Child and Adolescent Social Work Journal, 18(6), 401-416.

Pereda, N., Guilera, G., Forns, M., Gomez-Benito, J. (2009). The international epidemiology of child sexual abuse: A continuation of Finkelhor (1994). Child Abuse \& Neglect, 33, 331-342.

Phanichrat, T. \& Townshend, J. (2010). Coping strategies used by survivors of childhood sexual abuse on the journey to recovery. Journal of Child Sexual Abuse, 19(1), 62-78.

Phillips, A., \& Daniluk, J. (2004). Beyond 'Survivor': How childhood sexual abuse informs the identity of adult women at the end of the therapeutic process. Journal of Counseling \& Development, 82, 177-184.

Riessman, C. K. (2008). Narrative methods for the human sciences. California, USA: Sage Publications.

Ronen, T. (1996). Constructivist therapy with traumatized children. Journal of Constructivist Psychology, 9, 139-156.

Saha, S., Cheung, M., \& Thorne, L. (2011). A narrative exploration of the sense of self of women recovering from child sexual abuse. Counselling Psychology Quarterly, 24, 101-113.

Sanchez-Meca, J., Rosa-Alcazar, A., \& Lopez-Soler, C. (2011). The psychological treatment of sexual abuse in children and adolescents: A meta-analysis. International Journal of Clinical and Health Psychology, 11, 67-93. 
Sepúlveda, G. (2013). Psicoterapia evolutiva con niños y adolescents [Evolutive psychotherapy with children and adolescents]. Santiago: Mediterráneo.

Servicio Nacional de Menores [SENAME]. (2014). Bases técnicas específicas: Programa de protección especializado modalidad maltrato infantil grave y abuso sexual [Specific technical basis: specialized protection program, childhood maltreatment modality and child sexual abuse]. Available from: www.sename.cl.
Stith, S., Rosen, K., McCollum, E., Coleman, J. \& Herman, S. (1996). The voices of children: Preadolescent children's experiences in family therapy. Journal of Marital and Family Therapy, 22, 69-86.

United Nations Children's Fund [UNICEF] (2006). World report on violence against children. UNICEF.

Valles, M. (2003). Técnicas cualitativas de investigación social [Qualitative techniques of social research]. Madrid: Editorial Síntesis. 